\title{
2 I 26 Saphenous vein graft atherosclerotic plaque quantification utilizing magnetic resonance imaging and multidetector computed tomography: a comparison with intravascular ultrasound Gary YH Liew*1, Christopher J Hammett ${ }^{1}$, Benjamin K Dundon ${ }^{1}$, Karen SL Teo ${ }^{1}$, Matthew I Worthley ${ }^{1}$, Azfar G Zaman ${ }^{2}$ and Stephen G Worthley ${ }^{1}$
}

Address: ${ }^{1}$ Royal Adelaide Hospital, Adelaide, Australia and ${ }^{2}$ Freeman Hospital, Newcastle-Upon-Tyne, UK

* Corresponding author

from I Ith $^{\text {th }}$ Anual SCMR Scientific Sessions

Los Angeles, CA, USA. I-3 February 2008

Published: 22 October 2008

Journal of Cardiovascular Magnetic Resonance 2008, I0(Suppl I):A395 doi:10.1 186/I532-429X-I0-SI-A395

This abstract is available from: http://jcmr-online.com/content/I0/SI/A395

(c) 2008 Liew et al; licensee BioMed Central Ltd.

\section{Introduction}

The 10-year patency rate of saphenous vein grafts (SVG) has been reported to be $40 \%-60 \%$. Atherosclerotic plaque has been implicated in this late stage of vein graft disease. We evaluated SVG plaque quantification by magnetic resonance imaging (MRI) and multidetector computed tomography (MDCT) as compared to intravascular ultrasound (IVUS).

\section{Purpose}

To ascertain the feasibility and accuracy of plaque quantification utilizing MRI and MDCT as compared to IVUS.

\section{Methods}

Sequential patients $(\mathrm{n}=22)$ undergoing coronary angiography with anginal symptoms and significant saphenous vein graft lesions were enrolled. All patients had IVUS, MDCT (16-detector) and MRI using black-blood T1weighted imaging $(1.5 \mathrm{~T})$ performed. Cross-sectional images from IVUS and MDCT were analysed at $1 \mathrm{~mm}$ intervals along the entire length of the lesion. MRI images were obtained and analysed at $5 \mathrm{~mm}$ intervals. The sum of the plaque areas on these images gave the lesion volume. The MDCT and MRI images were analysed by two independent investigators. Spearman's correlation and BlandAltman plots were used where appropriate.

\section{Results}

MRI data were analysed for 18 patients ( $\mathrm{n}=19$ lesions) as 3 patients were unable to finish their scans and one patient's scan was degraded by artefact. The mean age of the SVGs was 13.95 years $( \pm 4.41$ years $)$. The interobserver variability as determined by coefficient of variance for assessing plaque volume for MDCT and MRI was $3.6 \%$ and $9.9 \%$ respectively. The correlation between MDCT and IVUS was better in mean luminal area $(\mathrm{r}=$ $0.87 ; \mathrm{p}<0.001)$ than mean vessel wall area $(\mathrm{r}=0.77 ; \mathrm{p}<$ $0.001)$. In contrast, MRI and IVUS correlation was better in vessel wall area $(\mathrm{r}=0.77 ; \mathrm{p}<0.001)$ than luminal area $(\mathrm{r}=0.59 ; \mathrm{p}=0.008)$. Spearman's correlation for plaque volume was better for MRI and IVUS $\left(r_{s}=0.97 ; p<0.001\right)$ compared to MDCT and IVUS $\left(\mathrm{r}_{\mathrm{s}}=0.85 ; \mathrm{p}<0.001\right)$. However, Bland-Altman plots (Figure 1) show plaque volumes by MDCT to be closer to IVUS (differences of mean = $186.9 \mathrm{~mm}^{3}$; SD $=239.1$ ) compared to MRI and IVUS (differences of mean $=437.5 \mathrm{~mm}^{3} ; \mathrm{SD}=407.9$ ).

\section{Conclusion}

Both black-blood MRI and MDCT are able to reliably quantify atherosclerotic plaque in SVGs when compared to IVUS. However, over estimation in plaque volumes is greater in MRI especially with increasing vessel size. The ability to noninvasively assess atherosclerosis in SVGs 

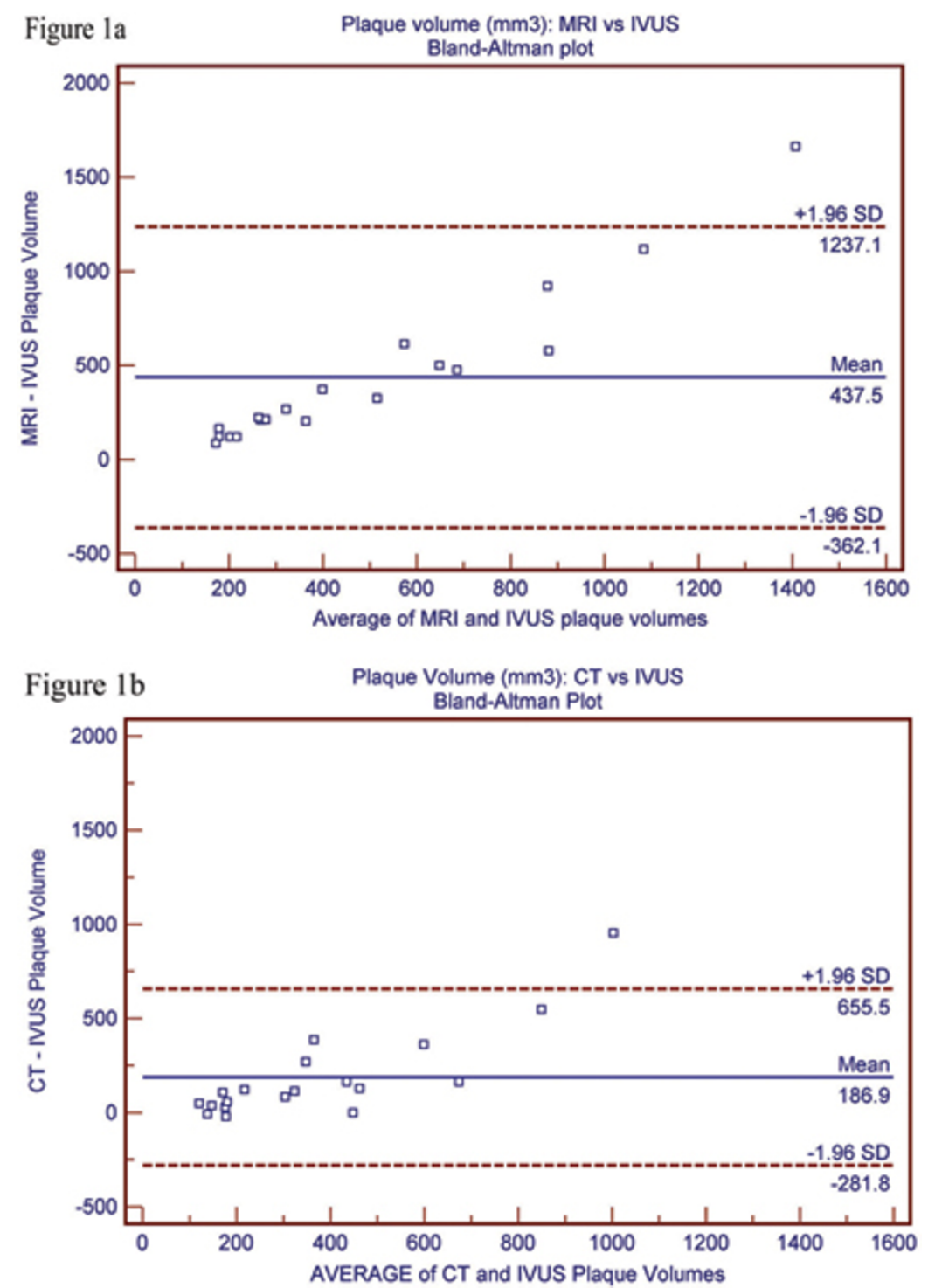

Figure I

Bland-Altman plots showing plaque volume $\left(\mathrm{mm}^{3}\right)$ : MRI vs IVUS (Ia) and plaque volume ( $\left.\mathrm{mm}^{3}\right)$ : CT avs IVUS (Ib).

may potentially lead to superior risk prediction for future cardiovascular events.
Publish with Biomed Central and every scientist can read your work free of charge

"BioMed Central will be the most significant development for disseminating the results of biomedical research in our lifetime. " Sir Paul Nurse, Cancer Research UK

Your research papers will be:

- available free of charge to the entire biomedical community

- peer reviewed and published immediately upon acceptance

- cited in PubMed and archived on PubMed Central

- yours - you keep the copyright

Submit your manuscript here:

http://www.biomedcentral.com/info/publishing_adv.asp
BioMedcentral 